\title{
Medical Writing
}

\section{Aide-mémoire for preparing a protocol}

\author{
M D WARREN
}

British Medical fournal, 1978, 1, 1195-1196

Reviewing some of the activities of the regional research committees in England and their equivalent in the Welsh Office, Williams ${ }^{1}$ " considered that the scheme is not yet widely used: "In some regions prospective researchers, especially those without previous experience, need a comprehensive and easily identifiable counselling service, so that the fund may be exploited in the way originally intended and the number of unsuccessful proposals reduced." The South-east Thames Regional Health Authority's regional research committee (chairman Dr D I Williams) is trying to meet some of these points. Members of the research committee, and many other people when approached by the committee, are only too willing to advise people wanting to do research. In addition the committee has produced an aide-mémoire, which is reproduced below. This aide-mémoire is intended to be a helpful reminder of the main points to be considered, and is not an official list of instructions for completing an application form.

\section{Aide-mémoire for preparing a protocol}

The questions and suggestions listed below are intended as an aide-mémoire for those planning a research project, whether this is to be a descriptive study, a clinical trial, or a survey. The protocol should set out the aims of the project, how these are to be achieved, how bias will be eliminated, the subjects or types of patients to be studied, the ethical aspects, and the proposed statistical analysis. It should establish that the expenditure of effort, time, and money is likely to be worth while. Planning and statistical advice should be sought at the preliminary stages of the study.

\section{(1) What is the problem?}

What are the aims and precise objectives of the study? What questions are to be answered? Is the purpose to evaluate a new treatment, procedure, or service? To obtain new facts about the causation or natural history of a disease or for the future planning and evaluation of a service?

(2) What is already known about the problem?

What are the gaps in present knowledge? How will the

Health Services Research Unit, University of Kent, Canterbury, Kent CT2 7NF

M D WARREN, FRCP, FFCM, professor and director proposed study contribute to our knowledge and understanding of the problem?

(3) Is the proposal a pilot or main study?

\section{(4) What design will be used in the project?}

Will the study be basically a laboratory project or a survey? Will it be a "trial" (or "intervention") of a treatment, procedure, or service (therapeutic, preventive, or educational)? Will it be a case-control study with randomised or matched controls? If a survey, will it be conducted by questionnaire, interview, or clinical examination? Will it be retrospective, cross-sectional, or prospective (cohort)? Is a "blind" or "double-blind" design proposed?

\section{(5) How are the subjects of the study to be chosen?}

What is the population from which the subjects will be drawn (the denominator in incidence and prevalence studies)? Are the subjects of the study the total population of a community or all patients with a certain diagnosis? What are the entry and exclusion criteria for choosing subjects? How are the controls to be chosen? Will a sample of the total population or of all potential subjects be examined? How is a sample to be obtained to ensure that it is representative of the total population? Attention must be paid to the definition of the criteria for selection, to the sampling methods, and to the number of subjects needed to obtain a significant result.

\section{(6) What data are to be collected, and why?}

What factors (variables) are already thought to affect the outcome? What factors contained in the new hypothesis are being tested? What factors (if present) might distort the reliability of representativeness of the results? What are the indicators or measures of the outcomes of the trial or experiment ? The amount of data collected should be limited, though measures of different dimensions of outcome should be used when possible.

(7) What are the treatment schedules or other activities forming the "intervention" in the study, and how are the variables to be defined and measured?

The techniques, dosage, programmes of treatment, prophylaxis, other activities, etc, must be standardised; this is especially important in multicentre studies. Explicit decisions must be taken about how the presence or absence of disease is to be 
determined (for example, hypertension and diabetes), how severity and duration are to be measured, and how social and demographic variables are to be defined and measured (for example, marital state, occupation, and social class). If possible, the proposed definitions and measurements should be consistent with those used in comparable studies; if they are not, the reasons for the differences should be stated.

(8) How are the data to be collected and the measurements to be made?

Have the methods been tested ? Are they valid (that is, do they actually measure what they are intended to)? Are they reliable (that is, can they be repeated to yield the same results)? Are they sensitive (that is, can they identify all positive cases)? Are they specific (that is, can they identify only positive cases) ? Will data be collected by observation, examination, interview, or from record forms? Will special recording forms be needed? Who will collect the data? What training will they need ? Should an independent observer make the baseline or outcome measurements (or both)? What checks and controls will be used to maintain accuracy and objectivity?

\section{(9) How will the data be processed and analysed?}

Will this be done by computer or some other method? Must the data be coded and punched on to cards? If so, who will do this? How will the analysis proceed? How will the data be presented? What form of publication is likely to result?

\section{(10) What problems of ethics and etiquette does the project raise?}

Are patients' rights properly observed? How are the consent and collaboration of patients, doctors, nurses, social workers, and others to be obtained ? How is the confidentiality of the data to be ensured ? What agreements are to be made about publication? Has the project been approved by the ethics committee?

(11) What arrangements are to be made for treating or referring patients for whom new needs come to light as a result of the project?

Can the local services cope ? Or will special arrangements be needed?

(12) What is the expected timetable for the study?

In what order will the different stages of the investigation be carried out? It is helpful to set out what is to be done and by whom in chronological order with estimates of the duration of each activity. Enough time should be allowed for analysing the data and preparing the report (that is, the presentation, synthesis, and interpretation of the raw data).

\section{(13) What will the project cost?}

What will be the cost in manpower, including the time of the main investigator? What will be the cost of capital equipment ? What will be the cost of additional salaries (plus pension and National Insurance contributions), rent for accommodation, travelling and subsistence, stationery, printing, postage, telephone, photocopying, administrative costs, and overheads? What outside help and advice will be needed, and how much will it cost? What is already available ? What additional resources are required?

I thank $\mathrm{Dr} \mathrm{D}$ I Williams, chairman of the regional research committee, for permission to report this aide-mémoire; Dr J R Butler, of the Health Services Research Unit, for help in compiling it; and the members of the research committee and several other consultants in the region for commenting on drafts of the document.

\section{References}

1 Williams, B T, British Medical fournal, 1977, 2, 944

2 Williams, B T, British Medical fournal, 1978, 1, 85

\section{Further reading}

(Short book texts available in paperback editions)

Abramson, J H, Survey Methods in Community Medicine. London, Churchill Livingstone, 1974.

Barker, D J P, and Rose, G, Epidemiology in Medical Practice. London, Churchill Livingstone, 1976.

Beveridge, W I B, The Art of Scientific Investigation. London, Heinemann, 1961.

Calnan, J, One Way to Do Research. The A-Z for Those Who Must. London, Heinemann, 1976

Clinical Trials Unit, Department of Pharmacology and Therapeutics, London Hospital Medical College, British Medical fournal, 1977, 1, 1323.

Lock, S, Thorne's Better Medical Writing. London, Pitman Medical, 1977. (Hard covers only.)

Lionel, N D W, and Herxheimer, A, British Medical fournal, 1970, 3, 637. Medical Research Council, Responsibility in the Use of Medical Information for Research, in Annual Report 1972-73, p 10. London, HMSO, 1973.

Stacey, M, Methods of Social Research. Oxford, Pergamon Press, 1969.

Swinscow, T D V, Statistics at Square One. London, British Medical Association, 1976

(Accepted 2 March 1978)
Does clomipramine hydrochloride (Anafranil) or lithium cause weight gain or acne?

Clomipramine can cause change in appetite and an increase (or decrease) in weight, but it has not been reported as causing acne. Lithium treatment can also be associated with weight gain, and although some skin troubles occasionally occur, acne does not.

What constitutional upsets can travellers expect after long jet flights? What is the reason for a "flu-like" illness.

I have not met this "flu-like" illness after long flights. Certainly crews do not complain of it, and neither I nor my colleagues working in aviation medicine have experienced it. There is much individual variation and adaptability to long jet flights. Often on an aircraft the mucus membranes tend to become dry, which suggests to the pituitary that the individual is becoming dehydrated so that fluids are con- served. If this occurs there is a diuresis eight to 12 hours after the flight. Transmeridian flights upset the circadian rhythm and put the bodily function out of phase, causing principally digestive, sleep, and bowel rhythm upsets.

$A$ mother aged 31 had a minor degree of spina bifida which was repaired leaving a 15-cm scar. She has had a normal child. What is the likelihood of a subsequent child having spina bifida and what is the earliest stage of pregnancy at which amniocentesis is commonly carried out?

The proportion of children of adult survivors with spina bifida cystica who have a neural tube malformation is about $3 \%{ }^{1}$ This will be little affected by the fact that she already has one normal child. Amniocentesis for alpha-fetoprotein estimation is normally carried out at the 16 th week of gestation.

${ }^{1}$ Carter, C O, and Evans, K, Lancet, 1973, 2, 924. 